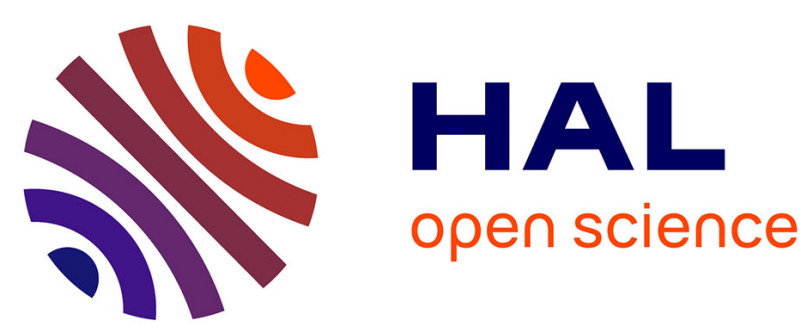

\title{
Developing a toolkit for mapping and displaying stone alteration on a web-based documentation platform.
}

Chiara Stefani, Xavier Brunetaud, Sarah Janvier-Badosa, Kévin Beck, Livio de Luca, Muzahim Al-Mukhtar

\section{- To cite this version:}

Chiara Stefani, Xavier Brunetaud, Sarah Janvier-Badosa, Kévin Beck, Livio de Luca, et al.. Developing a toolkit for mapping and displaying stone alteration on a web-based documentation platform.. Journal of Cultural Heritage, 2013, 10.1016/j.culher.2013.01.011 • hal-00939206

\section{HAL Id: hal-00939206 https://hal.science/hal-00939206}

Submitted on 14 Nov 2019

HAL is a multi-disciplinary open access archive for the deposit and dissemination of scientific research documents, whether they are published or not. The documents may come from teaching and research institutions in France or abroad, or from public or private research centers.
L'archive ouverte pluridisciplinaire HAL, est destinée au dépôt et à la diffusion de documents scientifiques de niveau recherche, publiés ou non, émanant des établissements d'enseignement et de recherche français ou étrangers, des laboratoires publics ou privés. 


\section{Developing a toolkit for mapping and displaying stone alteration on a web- based documentation platform}

\section{Chiara Stefani}

Modèles et simulations pour l'Architecture, l'urbanisme et le Paysage CNRS/MCC MAP, Ecole Nationale Supérieure d'Architecture de Marseille, 184 Av. de Luminy, 13288 Marseille Cedex 9, France.

Centre de Recherche sur la Matière Divisée UMR 6619, 1B rue de la Férollerie, 45071 Orléans Cedex 2, France

Tel: $+33(0) 491827179$

Fax: $+33(0) 491827171$

E-mail: chiara.stefani@map.archi.fr (Corresponding author)

\section{Xavier Brunetaud}

Centre de Recherche sur la Matière Divisée UMR 6619, 1B rue de la Férollerie, 45071 Orléans Cedex 2, France

Université d'Orléans, Ecole Polytechnique d'Orléans, 8 rue Léonard de Vinci, 45072, Orléans Cedex 2, France

Tel: $+33(0) 238255374$

Fax: $+33(0) 238255376$

E-mail:xavier.brunetaud@univ-orleans.fr

\section{Sarah Janvier-Badosa}

Centre de Recherche sur la Matière Divisée UMR 6619, 1B rue de la Férollerie, 45071 Orléans

Cedex 2, France

Tel: $+33(0) 238255365$

Fax: $+33(0) 238255376$

E-mail: sarah.janvier@cnrs-orleans.fr

\section{Kévin Beck}

Université d'Orléans, Ecole Polytechnique d'Orléans, 8 rue Léonard de Vinci, 45072, Orléans Cedex 2, France

Centre de Recherche sur la Matière Divisée UMR 6619, 1B rue de la Férollerie, 45071 Orléans Cedex 2, France

Tel : $+33(0) 238255365$

Fax: $+33(0) 238255376$

E-mail:kevin.beck@cnrs-orleans.fr

\section{Livio De Luca}

Modèles et simulations pour l'Architecture, l'urbanisme et le Paysage CNRS/MCC MAP, Ecole Nationale Supérieure d'Architecture de Marseille, 184 Av. de Luminy, 13288 Marseille Cedex 9, France.

Tel: $+33(0) 491827166$

Fax: +33(0)4 91827171

E-mail: livio.deluca@map.archi.fr

\section{Muzahim Al-Mukhtar}

Université d'Orléans, Ecole Polytechnique d'Orléans, 8 rue Léonard de Vinci, 45072, Orléans

Cedex 2, France

Centre de Recherche sur la Matière Divisée UMR 6619, 1B rue de la Férollerie, 45071 Orléans

Cedex 2, France

Tel: +33(0)238257881

Fax: +33(0)23825 5376

E-mail:muzahim@cnrs-orleans.fr 


\begin{abstract}
Stone conservation at Chambord Castle and monitoring of its changes over time is actually an urgent necessity in order to preserve and enhance this historic and tourist site. Its porous stones suffer from degradation problems depending on physical and chemical parameters that are the origin of frequent restorations.

The goal of this research is to supply authorities of the castle with a tool for scientific monitoring and decision support, based on the acquisition of alteration mapping and on the estimation of degradation patterns, in order to permit rational programming operations of restorations.

This paper proposes an approach for digital documentation about the conservation state of buildings. The approach is based on the connection between a structured 3D model and structured 2D mapping data. In particular, in the NUBES web platform, a specific interface has been implemented, permitting the display and cross-reference of 2D mapping data on the 3D model in real time, by means of structured 2D layer-like annotations concerning stone degradation, dating, and material.
\end{abstract}

\title{
Heritage conservation / 3D information system / stone degradation mapping / Vector graphics / 3D reconstruction / photomodeling
}

\section{Research aims}

The conservation of heritage buildings relies on diagnosis on current status and restoration interventions. Therefore, it is based on various kinds of investigations and analytical data. For that reason, the amount of heterogeneous data collected on heritage buildings (concerning historicalartistic documentation and technical and scientific records), should be relied in order to extract and display significant information. For this reason, the aim of this research is to define a new tool, belonging to a web-based documentation 3D platform, for the mapping and display of stone alterations on cultural sites. This tool could be used by different experts responsible for conservation (such as conservators, architects, scientists, curators, operators, analysts, consultants) and could support the stages of maintenance and monitoring that are preliminary to all restoration works.

\section{Introduction}

In the field of heritage conservation, various investigations are carried out to diagnose the current status of the building and future restoration interventions. Investigations concern several kinds of information such as historical-artistic documentation, technical and scientific documentation, and maintenance and monitoring actions. They are executed by different conservation experts (such as conservators, architects, scientists, curators, operators, analysts, consultants). Experts in heritage conservation handle a wide variety of data collection (such as photographs at different points in time, core samples, chemical analysis reports, description of 
interventions, etc) useful for several purposes. On one hand, the analysis of degradation pathologies allows experts to determine the current state of buildings; on the other hand, the detection of deterioration causes permits to estimate possible evolution of degradation in time, to define monitoring, restoring, and prevention operations. For this reason, technical data produced during the monitoring stage should be related to each other and crossed with historical and documentary data. This essential step will permit the experts to describe the visual appearance of monuments, determining the deterioration state and future phases of intervention.

\subsection{Related works}

In recent years, the field of Cultural Heritage took advantage of the use of digital collections of 3D data. Introducing and displaying 3D data collections have changed the working approach in respect to perception of information, ways of accessing and exchanging knowledge, and methods for interpreting and analysing data have been modified. Various techniques and approaches have been developed to acquire accurate $3 \mathrm{D}$ models, to structure information and to facilitate data manipulation/interpretation according to the analysis goals.

In the panorama of current research, some works focus on the acquisition of an accurate 3D model using photogrammetry and laser scanning techniques with the aim of analyzing 3D artifacts [1-4]. Such 3D acquisition techniques produce rigorous quantitative metrics data that, on one side, can be enriched by colorimetric values of textures or by reflectance values returned by material [5], and on the other side, allow three-dimensional information on the monument to be extracted [6], [7]. Furthermore, some hybrid [8], [9] and automatic [10] procedures are developed and include the acquisition, the geometric and radiometric processing, the $3 \mathrm{D}$ information reconstruction and the display of the visual appearance of the monument.

Some other research focuses on the structuring of digital collections in order to facilitate data retrieval and analysis. If certain works are based on the semantic characterization of generic 3D shapes [11] and on operators describing the sequence of the modelling process [12], [13], fewer works seem to semantically segment complex $3 \mathrm{D}$ models to annotate heterogeneous data in a display device [14], [15]. In this area, among research that connects heterogeneous data to the 
graphic representation of buildings, few studies aim at using various photogrammetric characterization techniques to define, manage, and display the state of conservation and the intervention operations of heritage sites [16-19]. These approaches combine hierarchical heritage data to information systems based on GIS (Geographic Information System), through the structuring of 2D geometric entities organized in multiple layers. Since data structured in hierarchical layers preserves geometric information, the displayed information can be filtered according to the analysis goal. Finally, very little research in the field of conservation uses these tools to improve the diagnostic process on buildings [1], [20-22].

\subsection{Fundamental problems and aims}

In the management of cultural heritage, two major problems have been revealed by these recent study applications.

Firstly, knowledge concerning the current state of conservation of monuments is related to the collection of a heterogeneous corpus of data concerning their morphology, the analysis of biological, physical-chemical and mechanical deteriorations, the definition of triggering factors of degradation (physical and environmental parameters) or, still, their history.

If the goal is to establish a link between the stages of description, analysis and monitoring of buildings, the fundamental problem of cross-referencing heterogeneous data should be taken into account. To this end, an important requirement is to assemble and display structured data in a unique system taking into account the 3rd dimension, and providing the relation between structured 3D geometric data and structured 2D mapping data.

Secondly, charges for the restoration of historic sites are often a compromise between the definition of intervention operations, their costs, and their length. The control of budgets is very complex: sometimes only urgent operations are performed and sometimes monitoring is difficult to accomplish. For this reason, it is necessary to consider technical solutions to cross-reference analytical data and to interpret it in a satisfactory way, in order to help experts to anticipate future changes and future restoration projects. 
This is the case in the Domain of Chambord, whose objective is to propose a plan of restoration operations over 12 years. The SACRE research program (http://www.crmd-sacre.com) aims to give managers a rational tool for monitoring and preventing stone damage. Particularly, it should facilitate site maintenance and monitoring, planning of future interventions, and execution of restoration actions. In order to achieve this goal, several steps have succeeded. Firstly, heterogeneous data on the site of Chambord was gathered (such as bibliographic information on the construction time and stone replacement, photograph campaigns on degradation, stone samplings, and meteorological data); secondly, the 3D metric information was collected in order to constitute a 3D model providing the basis for damage analysis. Finally, a specific interface for the description and analysis of stone pathologies was created. This interface has been integrated into the NUBES 3D Information System.

This paper is organized into the following way. Section 2 details the specific site of Chambord Castle and its data collection. Then, section 3 examines the methodological approach adopted for the 3D model reconstruction constituting part of this data set. Section 4 begins by laying out the guiding principles of the $3 \mathrm{D}$ information system adopted to collect data and then looks at the informatics development specific to the description of damage analysis. This section details the relation among data, specific queries and suggests some examples of possible application. Finally, the last chapter assesses some limits of the approach and some further studies.

\section{Methodology}

\subsection{Selection of site}

The Castle of Chambord, in the French region "Centre", is a significant example of the urgent need for new tools for managing cultural heritage and for predicting restoration campaigns. In fact, its XVIth century castle (the biggest French castle) is characterized by various and very sensitive types of limestone requiring expensive and regular restoration operations. Urgency and unpredictability of operations makes the control of operation budgets very complex. In fact, as major cracks appear regularly on stones of the main façade, stones need to be substituted for 
tourist market demand (the castle is one of the most visited in France). Thereby, this site provides an important amount of data about the history of restoration works executed in the past centuries and meanwhile needs the programming of future restoration works established on the basis of health and aesthetic criteria. The SACRE project involves three main parts of the castle: the South facade, the East Tower and the stables of the "Marechal de Saxe". Most of the examples referred to this article concern the East Tower.

\subsection{Data collection and organization}

Currently, a heterogeneous corpus of data has been gathered in order to describe and understand the history and the current degradation state of Chambord Castle (Fig. 1):

- Ancient documentary texts (notarial acts detailing purchase dates and types of stones), technical documents (quotation detailing cost estimation for restorations) and iconographic sources (historical photographs, plans, and engravings) issued from the departmental archives of Loiret (Orléans) and of Loir-et-Cher (Blois), from the DRAC (Orléans), and from the library of Architecture and Cultural Heritage [23].

- Lapidary signs have been detected on the surface of some stones. They consist of various different marks effectuated by master stonemasons and even workers in the XVIth century.

- Mapping of degradations, effectuated by in-situ observations, and laying on the glossary published by ICOMOS [24]; mapping of stone dating and stone provenance, by means of historical archives support. A comprehensive mapping is available on the south façade of the castle and the East tower.

- Sampling reports and corings based on observations on the site, concerning mineralogical and chemical analysis (Scanning Electron Microscopy, X-ray diffraction powder and mass, thermogravimetric analysis) and micro textural analysis (optical microscope and MEB, Helium pycnometer, Mercury porosimetry). 
- Meteorological data and sensor data (rainfall, wind direction and intensity, relative humidity, air and stone temperature) acquired on the East Tower since 2010 and actually ongoing.

- Topographic survey and point clouds of some parts of the castle, obtained by laser scanning performed with a FARO Focus 3D laser scanner equipped with a mounted camera for visual rendering.

- $3 D$ model of the most relevant parts of the building realised using measurements by tachometer and photogrammetry techniques, and constituting the graphic support to analyse surface alterations. See the next section for the methodology approach.

\subsection{Methodology for the 3D reconstruction}

Generally 2D approaches [17], [18], [25] for the analysis of surface degradations are based on two dimensional views (such as orthophotos) limiting the description of the conservation state to only the faces orthogonal to the direction of projection. In contrast with these methods, this approach is based on the 3D reconstruction of the building. In fact, 3D modelling provides complete spatial 3D data for the analysis of degradations. In this case, the 3D restitution of the geometry and the appearance of the castle is based on photogrammetric techniques [26]. The choice of the methodology used is based on a compromise between speed of execution, cost, and relevance of the collected data, in view of achieving the database. A comparative study between the use of photogrammetric techniques and surveying techniques to reconstruct the East tower is available at [27], [28]. The whole procedure is composed of various stages described in the following paragraphs for the East Tower of the Castle.

\subsubsection{Topographic survey}

This phase consists in localizing reference points on the whole monument by using a total station. 80 survey points have been acquired for the whole tower using a Leica total station. Topographic station changes have been made on the basis of 5-points triangulation so to minimize positioning error. These points allow us, on the one hand, to define the reference system of the 3D model 
obtained in the next phase, and on the other hand, to metrically validate the results of the phase of camera calibration and orientation. The coordinates of 5 of the topographic points are used to specify the localization of the same points in the 3D model, and it is based on a least square adjustment. This step allows the reference system of the 3D model and its scale to be obtained. The remaining topographic points can be used to estimate the uncertainty of the $3 \mathrm{D}$ model. Uncertainty is calculated by computing the standard deviation between the localization of a topographic point and its corresponding point on the 3D model. After having compared the coordinates of 40 points, the resulting standard deviation was about $2 \mathrm{~cm}$.

\subsubsection{Photomodeling}

This technique uses the principles of photogrammetry to obtain the 3D model of the building starting from photographs. In order to model the different parts of the Castle, we followed four main stages. For more details, see [29].

- Snapshot acquisition. By means of a digital bridge camera of 10 Million pixels, different acquisition techniques have been adopted according to the morphology of the main body. For instance, in the case of cylindrical parts (such as the East tower) an acquisition procedure by convergent axes has been used. Forty-three photographs have been acquired around the tower, covering the whole surface. A higher number of photographs (taken at different depth levels with $2 / 3$ focal distances) as well as a higher definition for the digital camera can improve the calibration process.

- Camera calibration. During this stage, the user manually selects the position of a set of control points on consecutive snapshots. The definition of each point on different snapshots allows an algorithm of the adopted software to detect the same points in space, by intersection of two epipolar straight lines (Fig. 2). By means of this resection procedure, the extrinsic parameters (camera position and orientation) and the intrinsic ones (focal length and distortion) are defined. The more points are detected on snapshots, the more the error level reduces. 
- 3D modeling. This phase is based on oriented photographs and geometric projections, and consists in creating 3D objects and surfaces. In order to get 3D geometrical objects coherent with the basic principles of the interface for degradation description, the 3D model has been conceived according to the following criteria: firstly, it has been necessary to structure the 3D model in smaller sub-elements established according to architectural criteria (such as spans and pillars on the façade); secondly, each 3D element has been conceived with perfectly jointed, unclosed and no secant surfaces. This second aspect is required for texture extraction needs (Fig. 3).

- Texture extraction. This stage consists in deforming or blending calibrated images to create textures that are so projected on the 3D model. Particularly, for each 3D object, one single texture has been extracted by defining the UV projection on the 2D map. By default, the software calculates an average plane when it extracts textures from the faces of objects. According to complexity of 3D shapes, the most adequate projection technique has been chosen so as to obtain homogeneous textures (Fig. 4). In the case of convex smooth surfaces (such as spans), a planar projection has been chosen; in the case of sharp-edged objects, the spherical projection has been preferred. In both cases, textures have been unfolded (meaning that faces are mapped in continuity according to the orientation of the face); however in the most complex cases, overlapping textures also required a manual unfolding. This technique often produces distorted textures, but optimises the readability of the texture file if compared with broken textures (obtained by multiple UV tiles).

\section{3D information system for conservation purposes}

This work is based on the central idea that, in order to evaluate stone degradation of buildings, multiple heterogeneous data is necessary and 3D metric information (photogrammetric survey techniques) should be related to two-dimensional metric information. In contrast with other approaches based on 2D layer-like annotation techniques [17], [19], in this research the adopted 
Information System is NUBES, an open source web platform for describing, analyzing, understanding, documenting and sharing heterogeneous data at the architectural scale [30], [31].

In order to collect data related to pathologies of stone in one single interface, this system was implemented to enrich the 3D model with a structured description of mappings concerning materials, degradations and the dating of stones.

\subsection{Main principles}

The NUBES platform is an information system based on a 3D database that provides 3D geometric objects associated with attributes specific to the domain of architecture. This interface is based on a three-part-architecture, as described in [31]:

- Storage of heterogeneous data. A MySQL database organizes rough data derived from survey, multiple representations and associated information according to different user profiles.

- Manipulation of three-dimensional geometric representations in real time. A 3D interactive scene (Virtools DEV) allows 3D representations to be downloaded, viewed and manipulated.

- Consultation and management of online data. PHP pages permit the user to access data stored in the database and provide interaction between the 3D scene and the database.

In order to identify the state of conservation of heritage buildings, this system has been implemented with a toolkit specifically conceived for recording cartographies on stone and displaying them on the fly on the 3D model (Fig. 5). Finally, the creation of a tool for managing response operations would allow both the monitoring of degradation and the facilitation of the management of interventions. Details on this set of tools will be described in the next paragraphs.

For this reason, the process of enrichment of information on the Chambord Castle stones is based on three main steps:

- The uploading of textures, belonging to digital models, obtained by various techniques such as laser scanning or image-based modelling. The 3D model will constitute a support 
which is detailed enough to gather all data acquired during the project (see next section for details).

- The recording of stone alterations and their display on the 3D model. A free web-based, Javascript-driven SVG editor permits the drawing/modifying of alterations in specific layers. Alterations are so saved directly in the database and uploaded on the fly in the 3D viewer.

- The display on the fly of crossing cartography mappings in the 3D scene. The 3D scene constitutes a privileged environment in which to consult cartographies, as architectural discontinuities and points of joining between the different elements are more readable.

Lastly, this platform allows the insertion of specific points in the 3D scene such as those corresponding to the photographs of details, iconography, meteorological data, lapidary signs or sensor data. These aspects and informatics implementations are detailed below.

\subsection{Cartography managing}

In order to qualify stone deteriorations, the NUBES platform has been integrated with a free webbased, Javascript-driven SVG editor available on the web [32]. This interface is conceived to draw surfaces and geometrical elements on a canvas and to manage colour and opacity tools. Moreover, it has been improved to allow alterations to be drawn and modified in specific layers on the 2D unfolded textures extracted from the 3D model. Moreover, it interacts directly with the database and the 3D scene, as detailed below.

\subsubsection{Texture upload}

The interface, conceived for the managing of alterations, interacts constantly with the 3D scene. As a consequence, at the selection of an architectural element in the 3D scene by the user, its texture is automatically projected on the $2 \mathrm{D}$ interface for drawing purposes. Specific layers are loaded according to database content. If cartography mappings are already drawn, the texture is loaded with existing patterns already stored in a SVG file (see section 3.2.3). 


\subsubsection{Drawing of patterns}

With the support of the texture, analysis studies can be conducted with non destructive techniques. Patterns can be drawn on specific hierarchical layers concerning three main categories of analysis on stones: degradations, dating, and material. Each category is structured in hierarchical sublayers, each of them containing sub-types. As an example, stone degradation category is divided in biological, physico-chemical and mechanical one; i.e. biological degradations contain the subtypes mosses and lichens (Fig. 6). During this stage, each bi-dimensional pattern can be moved from a layer to another one.

\subsubsection{Data storage}

When saving the document, the content of each layer (drawn vector patterns) is saved in the database and uploaded on the fly on the 3D model. From a technical point of view, dynamic tables are upgraded with new data about new patterns (area, barycentre paths, etc.), and a set of data is stored in the database (Fig. 7):

- Scalable Vector Graphic files for stratigraphic analysis purposes, (containing semantic data on 2D shapes and on the hierarchical structure of this geometry);

- raster images for 3D visualization purposes (one file for each layer and sub-layer).

In the database, cartographies can be saved, deleted or modified at any time of the process by means of customized tools.

\subsection{Data organization and display}

In this platform, a variety of data can be displayed and queried. Data display is possible by means of several basic tools:

- Specific point insertion. 3D representations are connected to heterogeneous data stored in the database such as sampling reports, analyses, corings, graphics, meteorological data, lapidary signs, oriented photographs, and other iconographic sources (such as engravings, historical photographs, and sketches). A procedure permits the linking of sources directly to the 3D model by means of reference marks (Fig. 8). For each added source, additional 
information concerning the author, the date, the category, the reference, etc. can be inserted into the database.

- Pattern display on the fly. Cartography mappings can be displayed, queried and compared directly on the 3D scene by means of a hierarchical list of items (concerning categories, types and sub-types). As multiple levels of layer can be selected at the same time, this tool constitutes an aid for the understanding of the most affected areas and possible relations between stone degradations, dating and provenance (Fig. 9).

- Statistical analyses. As patterns are described by geometric information, when saving cartography, for each pattern the area value is stored in dynamic tables of the database. Stored area values are used to display, at the selection of a 3D element, the percentage of surface affected by any pattern (Fig. 10). We are actually implementing this tool to display a graph for multiple selections.

- Intersection tool. An algorithm of computational geometry based on [33] has been developed in Javascript language. It calculates intersections between two paths so to extract the meet points, the common area and to automatically display the resulting path (Fig. 11). This feature allows first observations on the relation between the area affected by degradation and other qualitative aspects of stone (dating and provenance).

\subsection{Application examples for interpretation purposes}

In respect of the previous descriptions, the ultimate goal of the interface is to provide experts with new methods to cross reference data in order to find correlations between data. Event thought the actual data is still in process, some application examples can be mentioned.

This kind of study opens new fields of analysis for various experts. For example, historians and heritage conservators can benefit from a tool that centralizes the collected data, for an ad hoc consultation. In particular, in the case of the castle of Chambord, an analysis of the spatial distribution of the lapidary signs of stones could reveal precious information on the temporal progression of the construction site (Fig. 10). Moreover, scientists in the field of conservation could benefit from the comprehension of some specific degradation processes by crossing 
cartographic data for statistic goals (Fig. 11). This feature permits us, through the developed intersection tool, to quantify the degree of correlation that relates a specific degradation with a property parameter of the stones concerned (nature, date, sun exposure, etc.). In particular, statistical correlations could be defined between degradations and stone types (this query could help in defining relations between pathologies and materials) or between degradations and dating (so to underline relations between certain kinds of degradation and their temporal decay).

\section{Conclusions \& outlooks}

This paper has demonstrated a need for the widespread use of structured 2D/3D data in order to manage cartography degradation patterns, to cross and interpret data. Some technical limits and conceptual recommendations for further studies should be underlined.

From a technical point of view, this approach proposes a 3D model based mostly on unfolding textures. This method reveals a good solution in order to display architectural elements that can be hidden by overhanged parts. However, from a semantic point of view, the structuring of patterns is limited by the distorted appearance of textures. This limit can be overcome by manipulating directly photographs and by projecting semantic annotations, drawn on photographs, directly on the 3D scene.

From a conceptual point of view, this toolkit constitutes the basis for further studies consisting of several aspects. Research in the near future should concentrate on the comparison of alteration patterns with dating and provenance of stones by means of computational geometry. By means of the developed intersection tool, the statistical correlation (alterations/dating of stone or alteration/provenance of stone) should be integrated to the tools of the interface.

Secondly, further research might explore the implementation of this tool as a support to the simulation of restoration sequences. In this regard, an important limit is the difficulty in defining priority actions of restoration that are usually based on "objective" and "subjective" criteria (such as scientific and personal processes, socio-political criteria, tourist market demand, etc.). As a consequence, by regularly monitoring affected areas, this tool could enable the scientific extraction of information as been the basis for a subjective evaluation of sequences of restoration. In this 
sense, in order to evaluate the "economic weight" of restoration operations and to define priorities, different restoration assumptions could be represented and compared.

\section{References}

[1] S. Al-kheder, Y. Al-shawabkeh, and N. Haala, "Developing a documentation system for desert palaces in Jordan using 3D laser scanning and digital photogrammetry," Journal of Archaeological Science, vol. 36, no. 2, pp. 537-546, 2009.

[2] M. Johansson, "Explorations into the Behaviour of three Different High-Resolution Ground-based Laser Scanners in the Built Environment," in Proceedings of CIPA WG6, Corfu, Grece, 2002.

[3] P. Lerones, J. Fernández, Á. Gil, J. Gómez-García-Bermejo, and E. Casanova, “A practical approach to making accurate 3D layouts of interesting cultural heritage sites through digital models," Journal of Cultural Heritage, vol. 11, no. 1, pp. 1-9, 2010.

[4] J. D. Meneely, B. J. Smith, J. Curran, and A. Ruffell, "Developing a "non- destructive scientific toolkit' to monitor monuments and sites," in ICOMOS Scientific Symposium, Malta, 2009.

[5] L. Palaia, R. Sánchez, L. López, Á. Gil, J. Monfort, S. Tormo, P. Navarro, and M. A. Álvarez, "Procedure for NDT and Traditional Methods of Ancient Building Diagnosis by Using Thermograph, Digital Images and other instruments data Analysis," presented at the 17th World Conference on Nondestructive Testing, Shangai, China, 2008, pp. 25-28.

[6] W. Boehler, G. Heinz, and A. Marbs, "The potential of non-contact close range laser scanners for cultural heritage recording," in Proceeding of CIPA International Symposium, Potsdam, Germany, 2001.

[7] A. D. Styliadis, "Digital documentation of historical buildings with 3-d modeling functionality," Automation in Construction, vol. 16, no. 4, pp. 498-510, 2007. 
[8] L. De Luca, P. Veron, and M. Florenzano, "Reverse engineering of architectural buildings based on a hybrid modeling approach," Computers \& Graphics, vol. 30, no. 2, pp. 160-176, 2006.

[9] F. Remondino, S. El-Hakim, S. Girardi, A. Rizzi, S. Benedetti, and L. Gonzo, “3D Virtual reconstruction and visualization of complex architectures - The 3D-ARCH project," in Proceedings of the 3rd ISPRS International Workshop 3D-ARCH 2009, Trento, Italy, 2009, vol. XXXVIII-5/W1.

[10] M. Pierrot-Deseilligny, L. De Luca, and F. Remondino, "Automated Image-Based Procedures for Accurate Artifacts 3D Modeling and Orthoimage," in XXIIIth International CIPA Symposium, Prague, Czech Republic, 2011.

[11] M. Attene, F. Robbiano, M. Spagnuolo, and B. Falcidieno, "Characterization of 3D shape parts for semantic annotation," Comput. Aided Des., vol. 41, no. 10, pp. 756-763, 2009.

[12] R. Berndt, S. Havemann, and D. Fellner, "3D Modeling in a Web Browser to Formulate Content-Based 3D Queries,” in Web 3D, 2009, pp. 111-118.

[13] S. Havemann, V. Settgast, R. Berndt, and O. Eide, "The Arrigo Showcase Reloaded -towards a sustainable Link between 3D and Semantics," in VAST 2008, 2008, vol. 9, pp. 125-132.

[14] A. M. Manferdini, F. Remondino, S. Baldissini, F. Gaiani, and B. Benedetti, "3D Modeling and semantic classification of archaeological finds for management and visualization in 3D archaeological databases," presented at the 14th VSMM Conference, Limassol, Cyprus, 2008.

[15] A. M. Manferdini, and F. Remondino, "Reality-based 3D modeling, segmentation and webbased visualization," in EUROMED2010, Limassol, Cyprus, 2010, vol. LNCS 6436, pp. $110-124$.

[16] K. Nuyts, J. P. Kruth, L. Lauwers, M. Pollefeys, L. Qiongyan, J. Schouteden, P. Smars, K. Van Balen, L. Van Gool, and M. Vergauwen, "Vision on Conservation: VIRTERF," in International Symposium on Virtual and Augmented Architecture (VAA01), 2001, vol. Springer-Verlag,, pp. 125-132. 
[17] P. Salonia and A. Negri, "Historical buildings and their decay: data recording, analysing and transferring in an ITC environment," The International Archives of the Photogrammetry, Remote Sensing and Spatial Information Sciences, vol. 34 (Part 5, W12), 2003.

[18] S. Scolastico, "Innovative systems for 2D-3D documentation and conservation of Cultural Heritage," in MIA Journal, Saint Maximin, France, 2006, vol. 0, pp. 41-46.

[19] SICaR - Sistema Informatico per la Catalogazione dei cantieri di Restauro. 2003.

[20] K. Hinsch, K. Zehnder, H. Joost, and G. Gülker, "Monitoring detaching murals in the Convent of Müstair (Switzerland) by optical metrology," Journal of Cultural Heritage, vol. 10, no. 1, pp. 94-105, 2009.

[21] L. Pecchioli, F. Mohamed, and M. Carozzino, "ISEE: accessing information navigating in a 3D virtual environment- the case study of the crypt in St. Servatus in Quedinburg, SaxonyAnhalt (Germany)," 2009.

[22] K. Zehnder and A. Voûte, "Monitoring detaching murals in the Convent of Müstair (Switzerland) by mirror micrometry," Journal of Cultural Heritage, vol. 10, no. 1, pp. 493$500,2009$.

[23] S. Badosa, K. Beck, X. Brunetaud, and M. Al-Mukhtar, "A historical study of Chambord castle: A basis for establishing the health record of the monument," International Journal of Architectural Heritage, accepted 2011.

[24] MONUMENTS AND SITES, “ICOMOS-ISCS : Illustrated glossary on stone deterioration patterns," MONUMENTS AND SITES, 2008.

[25] C. Baracchini, P. Lanari, R. Scopigno, F. Tecchia, and A. Vecchi, "SICAR: geographic information system for the documentation of restoration analyses and intervention," in SPIE 5146, Munich, Germany, 2003, vol. 5146.

[26] L. De Luca, La photomodélisation architecturale. Relevé, modélisation et représentation d'édifices à partir de photographies., Eyrolles. 2009. 
[27] X. Brunetaud, L. De Luca, S. Badosa, K. Beck, and M. Al-Mukhtar, "Application of digital techniques in monument preservation," European Journal of Environmental and Civil Engineering, accepted-2011.

[28] X. Brunetaud, C. Stefani, C. Canal, and Y. Ueberschlag, "Comparaison entre photomodélisation et acquisition par laser scanner pour la réalisation d'un carnet de santé de monument," presented at the 29ème Rencontres de l'AUGC, Tlemcen, Algérie, 2011.

[29] X. Brunetaud, L. De Luca, S. Badosa, K. Beck, and M. Al-Mukhtar, "A database gathering the mapping of degradations and the stonework dating in a $3 \mathrm{D}$ realistic model for the completion of a health record of monument," in Proceedings of 8th International Symposium on the Conservation of Monuments in the Mediterranean Basin, Patras, Greece, 2010.

[30] L. De Luca, C. Busayarat, C. Stefani, P. Véron, and M. Florenzano, "An integrated framework to describe, analyze, document and share digital representations of architectural buildings," in VAST2007 - Future technologies to empower heritage professionals, Brighton, UK, 2007.

[31] L. De Luca, C. Busayarat, C. Stefani, P. Véron, and M. Florenzano, "A semantic-based platform for the digital analysis of architectural heritage," Computers \& Graphics., vol. 35, no. 2, pp. 227-241, 2011.

[32] Google, "svg-edit. A complete vector graphics editor in the browser," 2010. [Online]. Available: http://code.google.com/p/svg-edit/.

[33] K. Lindsey, Kevin Lindsey Software Development. 2000. 

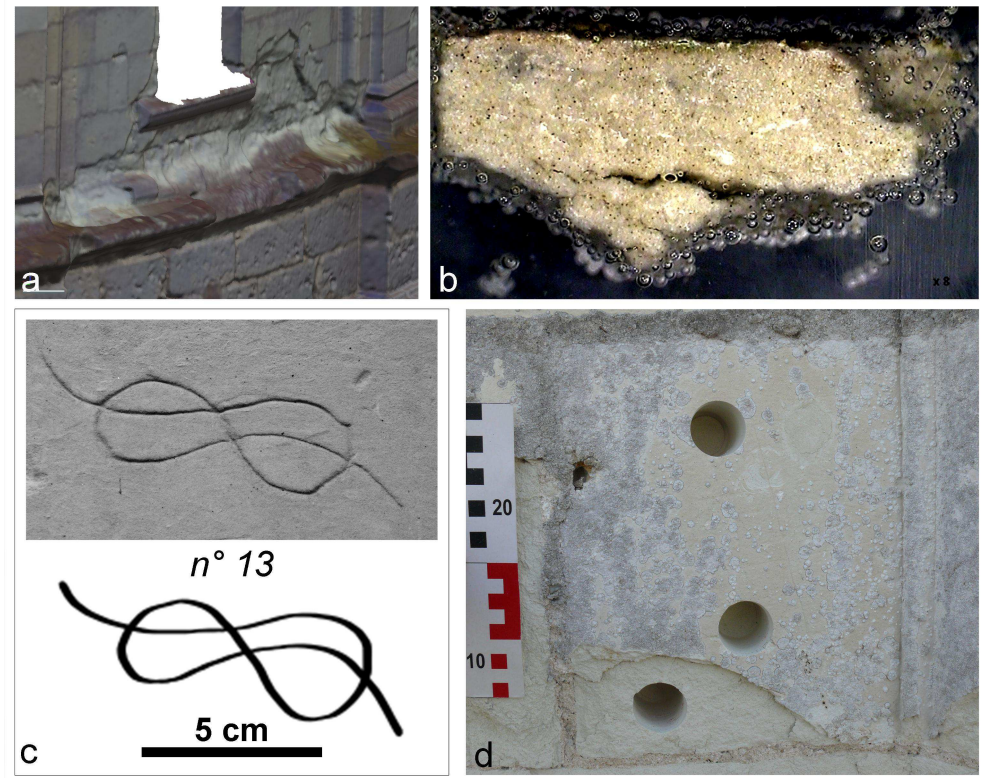

Figure 1. From up-left to bottom-right, collection of data concerning: a) laser scan of a large spanning (East Tower); b) removed spalling observed by a binocular microscope (x8); c) lapidary signs at Chambord Castle; d) coring on a stone of the castle.
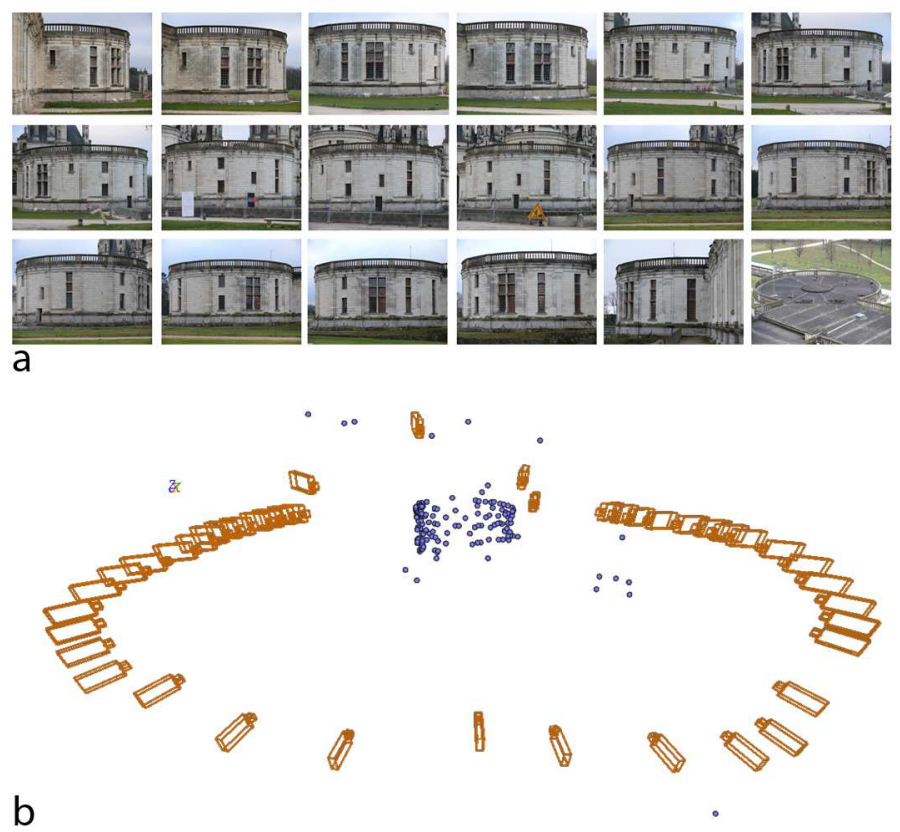

Figure 2. On the left, convergent photographs around the East Tower; on the right, spatial camera calibration and set of $3 \mathrm{D}$ coordinates of the tower. 


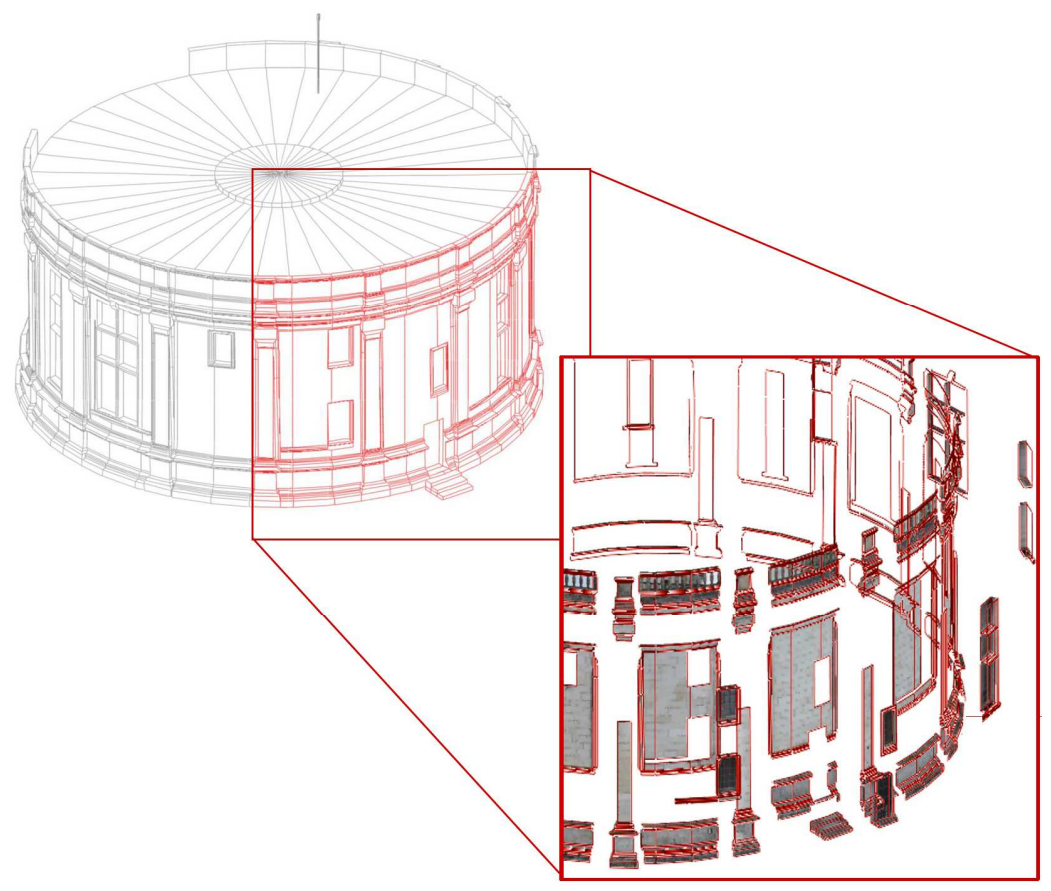

Figure 3. 3D model of the East Tower realised by photomodeling techniques, structured according to architectural criteria.
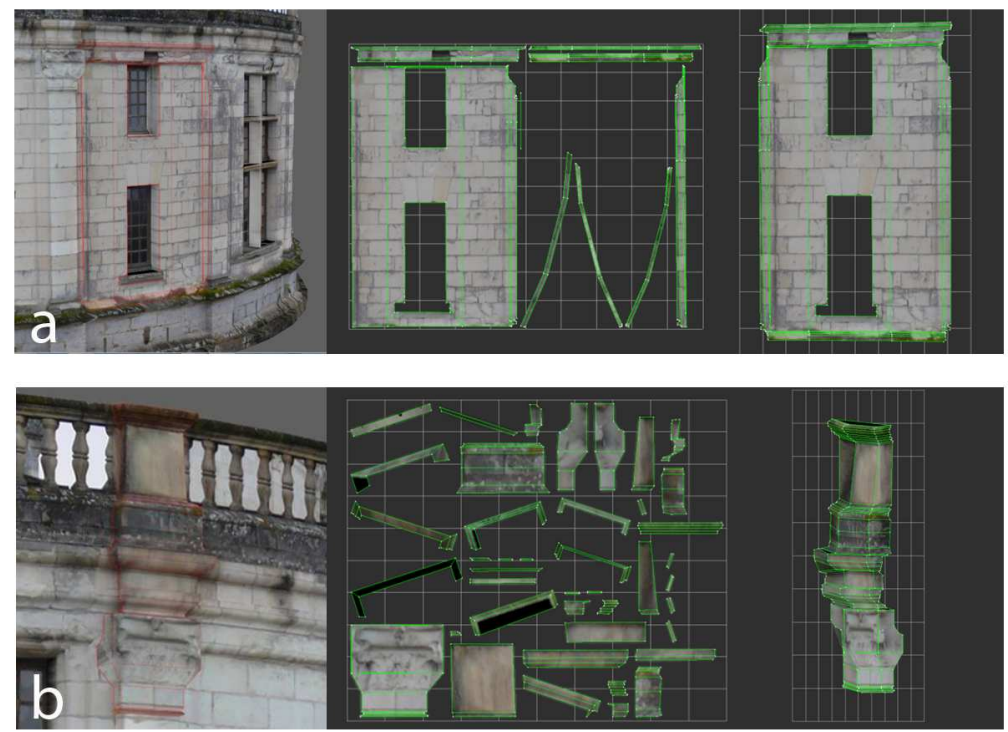

Figure 4. Upper figures: texture extraction by cubic and planar projection; bottom figures: texture extraction by cubic projection and spherical one with unfolded textures. 


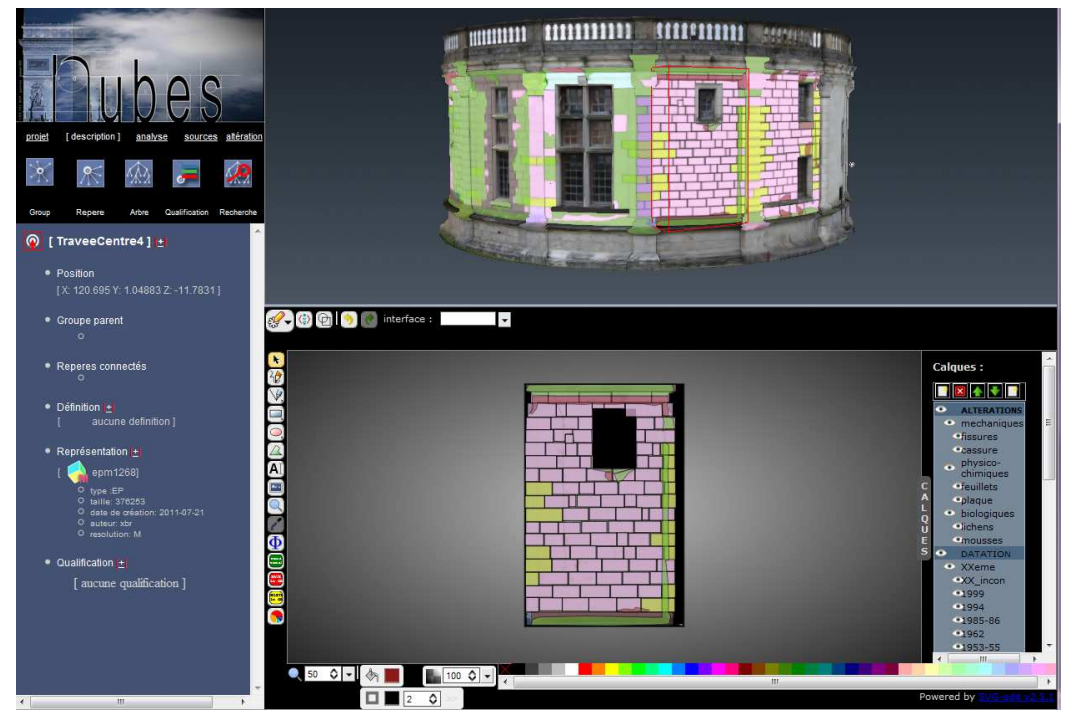

Figure 5. Interface of the NUBES platform specific to the stone degradation pattern documentation.

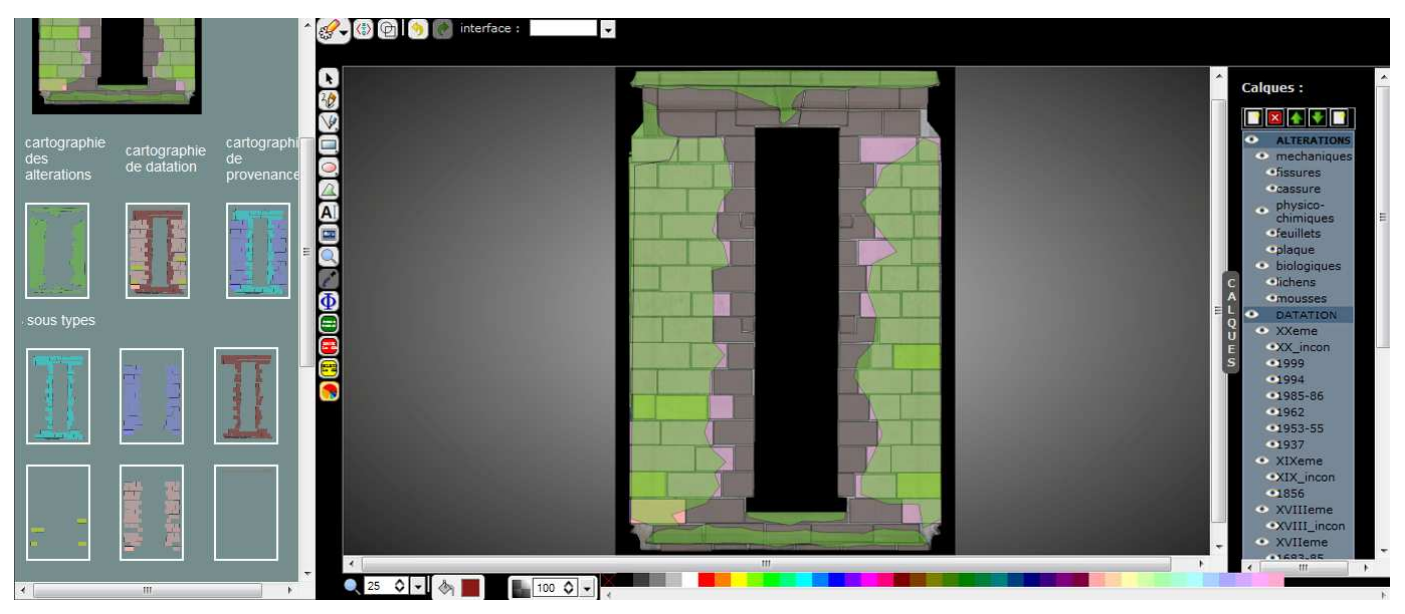

Figure 6. Interface implemented basing on svg-edit free editor according to conservation purposes.

On the right, hierarchical layers concerning different cartography types. 


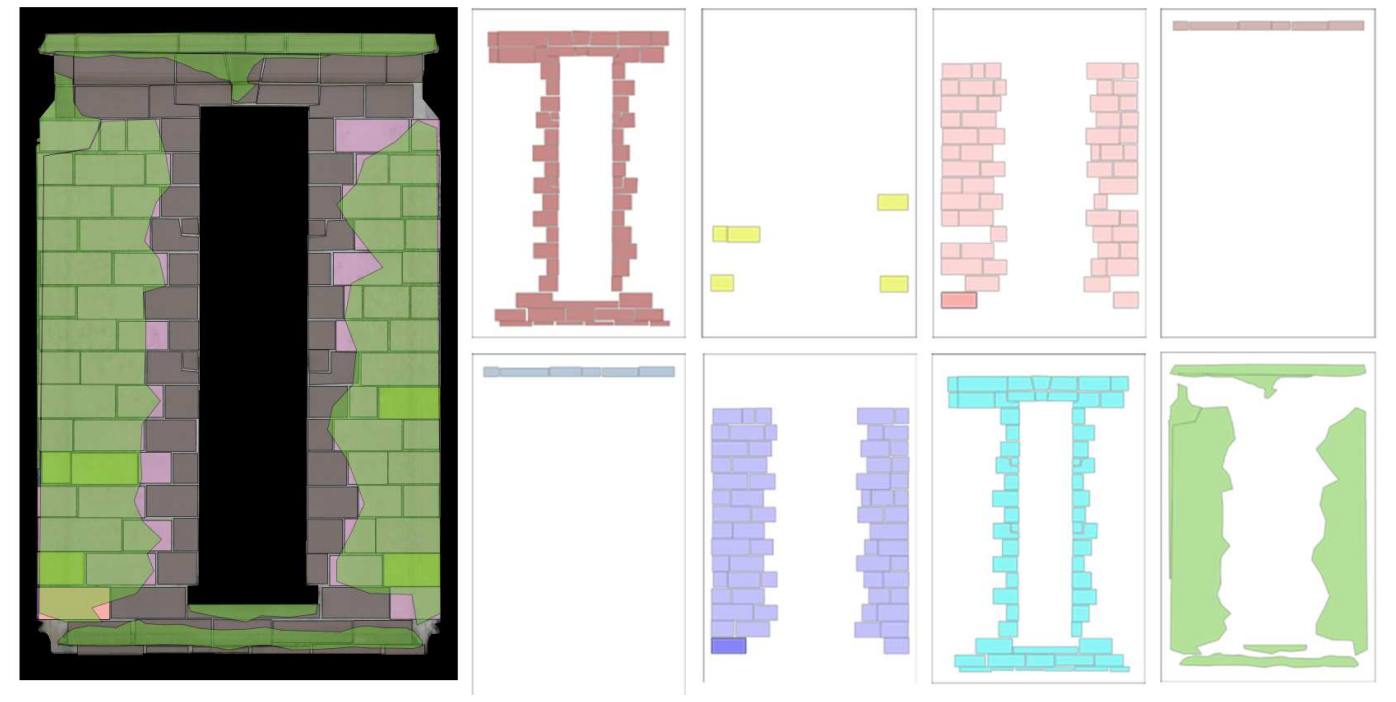

Figure 7. Example of set of images (vector and raster) stored in the database for a span. 


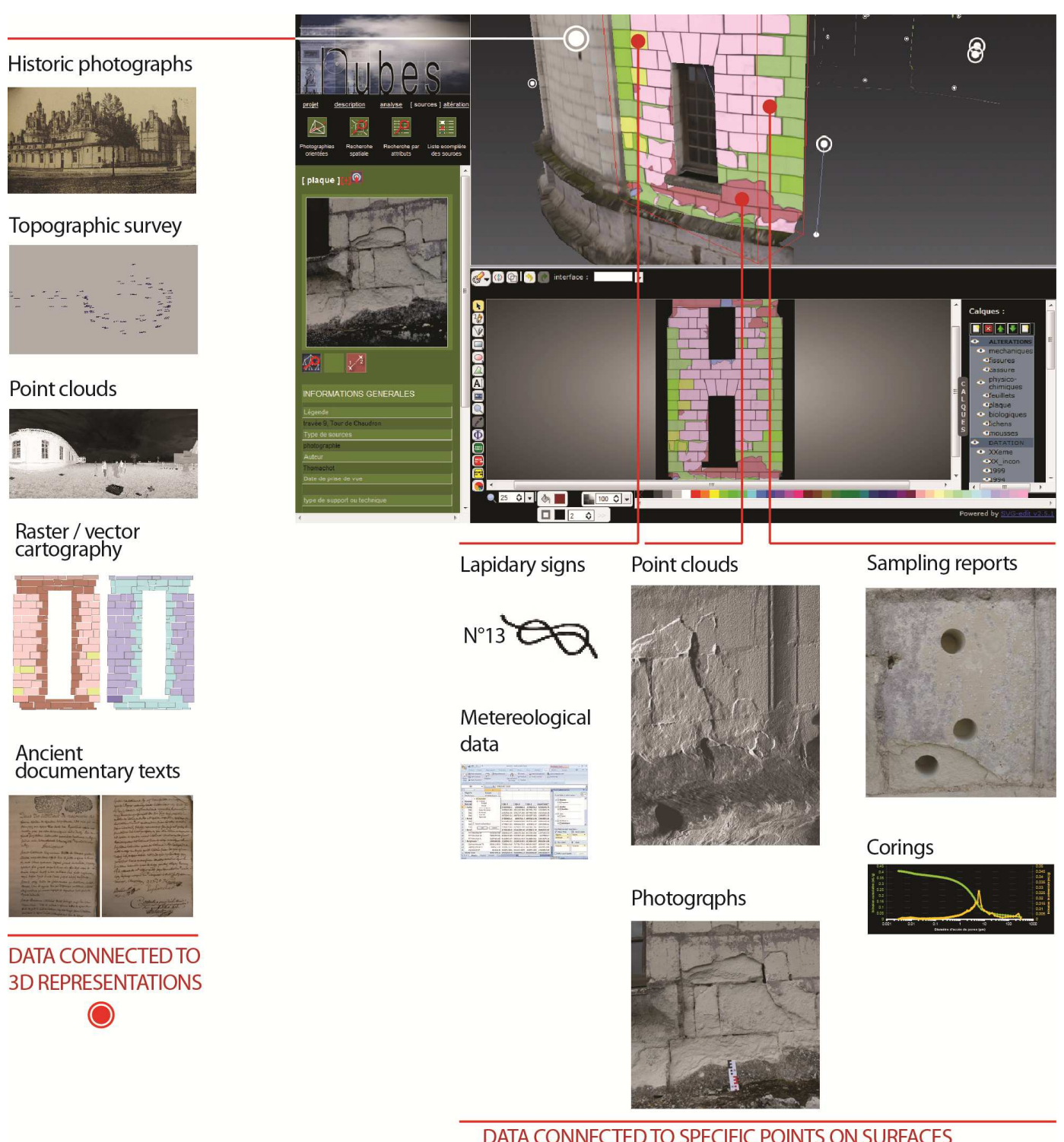

DATA CONNECTED TO SPECIFIC POINTS ON SURFACES

Figure 8. Data collection in the database. Sources can be connected to the 3D model (on the left) or to a specific point on the surface (on the bottom-right part). 


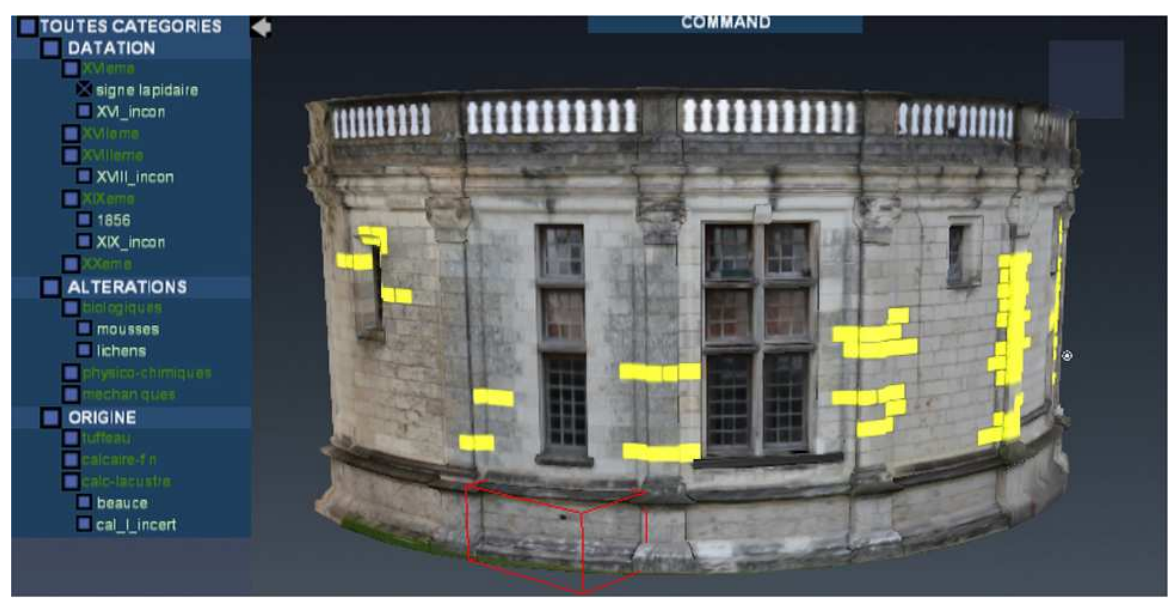

Figure 9. Example of cartography display: layer containing lapidary signs on the East Tower is selected.

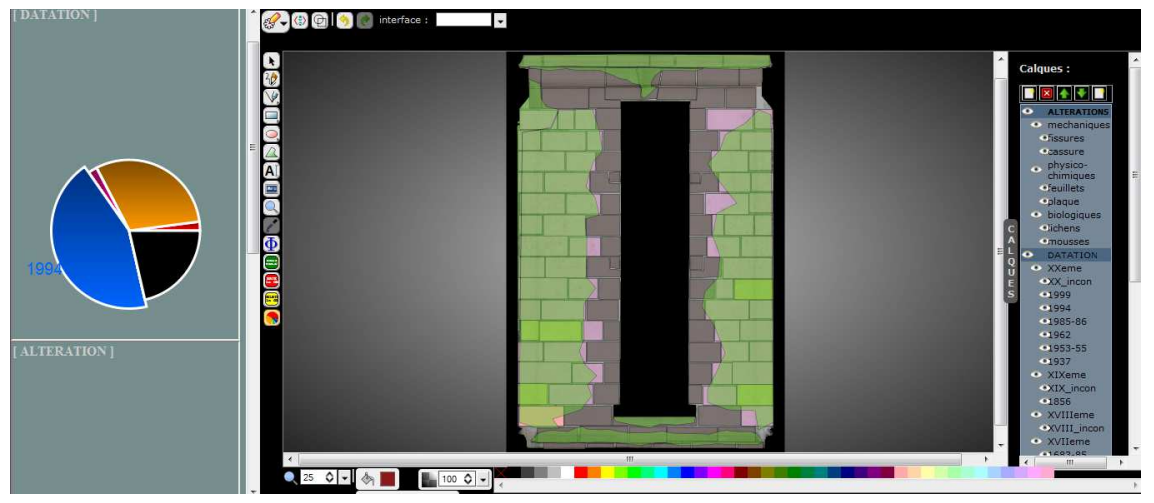

Figure 10. Statistical visualization of patterns concerning stone dating of the East Tower.

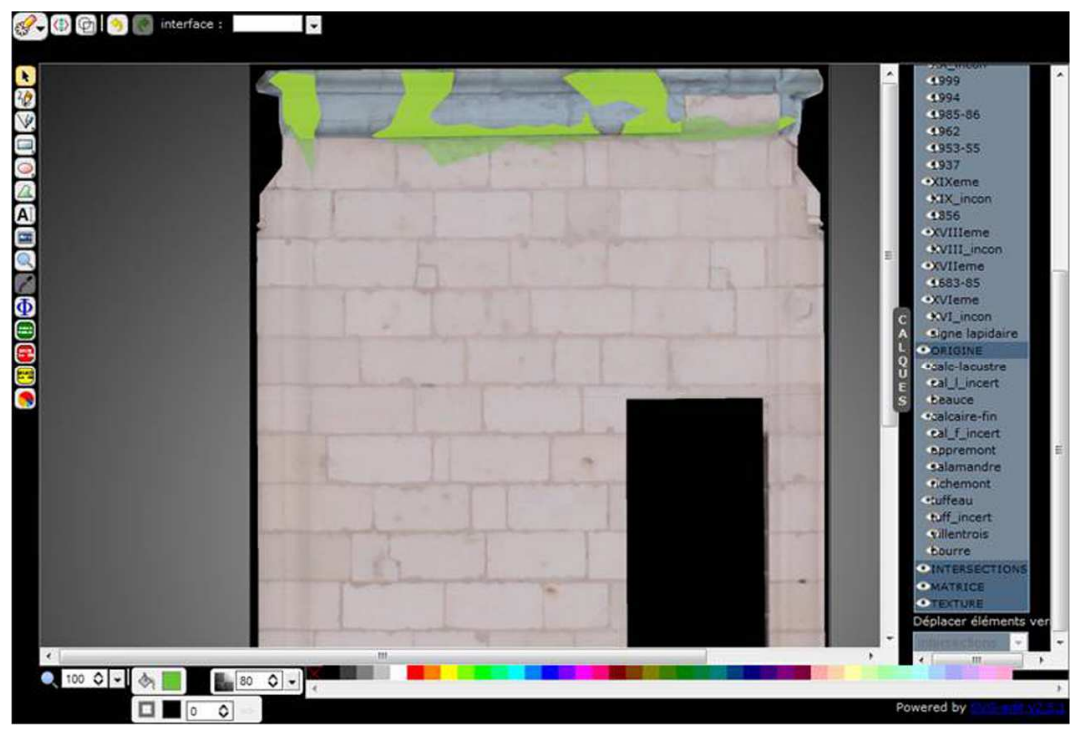

Figure 11. Automatic intersection area displayed on the $2 \mathrm{D}$ editor at the selection of two paths. 